\title{
TEORI DAN PRAKTEK EQUIVALENSI DALAM PENERJEMAHAN ENGLISH-INDONESIA
}

\author{
Gaguk Rudianto \\ Universitas Putera Batam (UPB), Batam, Indonesia \\ gagukrudianto@gmail.com \\ Yunisa Oktavia \\ Universitas Putera Batam (UPB), Batam, Indonesia \\ Yunisaoctavia@gmail.com
}

\begin{abstract}
Translation does not only translate from the source language (ST) to the target language (TT) because if it is done, the translation results or (TT) will not be accepted by the target language user and will not have the same effect as the source language. This is called the concept of equivalence. Equivalence is a problem that can not only be accepted by users of the target language which is also in accordance with the context of the culture, customs and habits of the local community, but this concept is essentially the result of the translated text having the same impact between the source language and the target language. This article analyzed the concept of theoretical and practical equivalence of translation from English to Indonesian or vice versa. The purpose of writing this article is to reveal the equivalence of translation and at the same time reveal translation errors that often occur in society. The data collection method used in this article is SBLC or free-to-talk (Sudaryanto, 1993). While the data analysis method is equivalent which was also written by the same expert.
\end{abstract}

Keywords: Equivalency and Translation Practice

\section{LATAR BELAKANG}

Penerjemahan adalah suatu kegiatan linguistik yang intinya menuliskan ulang pesan yang ada pada Bahasa sumber (ST) ke dalam pesan dari Bahasa sasaran (TT). Dalam aktivitas ini memang tidak dapat dipandang sebelah mata karena selama sumber-sumber ilmu pengetahuan berasal dari negara lain maka keberadaan penerjemah menjadi sangat vital karena tanpa penerjemah kita tidak akan dapat memahami apa saja yang ditulis dalam Bahasa asing tersebut. Coba kita bayangkan, misalnya kita tidak akan pernah mengetahui 
Vol. 3 No. 1

Juni 2021

e- ISSN 2685 - 0559

p- ISSN 2684 - 673X

perkembangan tehnologi dan informasi kalau saja tidak ada seorangpun yang menerjemahkan buku-buku tetrebut. Kita tidak akan bisa mengoperasikan suatu mesin apa saja kalau saja tidak ada seorangpun yang dapat menerjemahkan buku manual dari mesin tersebut. Hal ini menunjukkan betapa pentingnya peranan penerjemah dalam perkembangan di segala bidang termasuk technology dan infomasi.

Perkembangan penerjemahan pada masa mileneal sekarang ini sungguh sangat mengagumkan. Perkembangan ini ditandai dengan banyaknya penemuan translating machine yang mampu menerjemahkan berbagai Bahasa dalam hitungan detik saja. Sebut saja disini adalah "Google translate". Google translate adalah mesin penerjemahan yang dikembangkan oleh Google pada bulan April 2006. Pada awalnya program ini dipergunakan utuk pelayanan terjemahan mesin statistik dengan menggunakan algoritma dan dengan akurasi tata Bahasa yang sangat buruk. Google translate terus berbenah diri hingga pada bulan Januari 2010 Google meluncurkan aplikasi Android dan versi IOS pada Februari 2011 untuk berfungsi sebagai penerjemah pribadi portabel. Pada tahun yang sama di bulan kedua program tersebut telah diintegrasikan ke dalam browser seperti Chrome dan program tersebut mampu mengucapkan teks, secara otomatis mengenali kata-kata dalam gambar dan menemukan teks dan bahasa yang tidak dikenal.

Guna meningkatkan kualitas hasil penerjemahan pada Mei 2014, Google mengakuisisi word Lense untuk meningkatkan kualitas terjemahan visual dan suara. Program ini mampu memindai teks atau gambar dari perangkat seseorang dan menerjemahkannya secara instan.

Permasalahan yang paling krusial dalam penerjemahan adalah equiavalensi atau kesetaraan. Hal ini terjadi karena penerjemahan tidak hanya menerjemahkan suatu teks Bahasa sumber (ST) ke dalam suatu teks Bahasa sasaran (TT) saja, tetapi dalam penerjemahan ada beberapa hal yang perlu diperhatikan baik dari sudut pandang linguistik maupun dari sudut pandang budaya dari Bahasa sasaran. Inti dari permasalahan adalam artikel ini adalah mengungkapkan equivalensi baik secara teoritis maupun prakteknya dari hasil terjemahan yang bererad di masyarakat.

\section{TEORI EQUIVALENESI}

Beberapa teori ekuivalensi terjemahan yang disebutkan oleh Panou dalam jurnal Equivalence in Translation Theories: A Critical Evaluation adalah teori yang dicetuskan oleh Vinay and Darbelnet (1958), Jakobson (1959), Nida and Taber (1969), Catford (1965), House (1997), Koller (1979), Newmark (1981), Baker (1992), dan terakhir 
Vol. 3 No. 1

Juni 2021

e- ISSN 2685 - 0559

p- ISSN $2684-673 X$

adalah Pym (2010). Mengingat keterbatasan jumlah halaman dalam jurnal ini, penulis hanya membahas Equivalensi berdasarkanVenay and Dalbernet dan Cartford saja.

1. Jean Paul Venay and Jean Dalbernet

Dalam menerjemahkah dari Bahasa Perancis ke Bahasa Inggris mereka menggunakan 7 prosedure yaitu a) borrowing, b) calque, c) literal translation, d) transposition, e) modulation, f) Equivalence dan g) adaptation. Nomor a sampai nomor c dikategorikan ke dalam penerjemahan direct atau penerjemahan literal. Sedangkan sisanya disebut dengan oblique translation.

\section{a. Borrowing}

Borrowing adalah pinjaman suatu kata yang berasal dari Bahasa lain yang diadopsi ke dalam Bahasa itu untuk dijadikan suatu kosa kata baru. Peminjaman ini terjadi karena adanya suatu kebutuhan (Cambell, 1998). Sedangkan menurut Linguist Indonesia Kridalaksana $(1993,156)$ Kata pinjaman adalah kata yang berasal dari pengenalan elemenelemen fonologis, gramatikal, atau leksikal dalam bahasa atau dialek lain karena kontrak atau peniruan identitas. Meminjam terjadi ketika satu bahasa menambah leksikonnya sendiri suatu kata atau morfem dari bahasa lain. Dalam proses peminjaman pelafalan Bahasa yang dipinjam sering kali disesuaikan dengan aturan fonologis bahasa peminjaman (Campbell 1998).
Misalnya international dipinjam dan disesuaikan ejannya dalam Bahasa Indonesia menjadi internasional, emotion menjadi emosi dan lain sebagainya.

Dalam penerjemahan peminjaman merupakan salah satu cara yang paling mudah dan paling gampang untuk menciptakan efek stylistic. Contohnya abstrak (Inggris), akses (Inggris), Pizza (Italia), adab (Arab), rezeki (Arab), demokrasi (Yunani), mitos (Yunani) dan lainlain.

b. Calque

Calque adalam peminjaman tingkat kata atau phrasa dari Bahasa lain dan dalam peminjaannya kata atau phrase tersebut telah diterjemahkan secara literal. Seperti pada proses peminjaman secara umum, claque juga mengalami perumahan makna. Contoh calque dalam Bahasa Inggris "coordinating minister" diterjemahkan menjadi Mentri coordinator dalam Bahasa Indonesia bukannya mentri koordinasi. Presiding judge (Inggris) diterjemahkan menjadi hakim ketua (Bahasa Indonesia) dan lain sebagainya.

c. Literal Translation

Proses Literal translation adalah proses penerjemahan kata demi kata dalam suatu teks dari Bahasa sumber (ST) ke dalam Bahasa sasaran (TT). Penerjemahan ini tidak mepertimbangkan kontek lain diluar dari apa yang terdapat dalam teks tersebut. Penerjemahan tingkat literal ini dapat dilakukan apabila 
antara Bahasa sumber (ST) dan Bahasa sasaran (TT) termasuk dalam rumpun Bahasa yang sama seperti penerjemahan Bahasa perancis ke Bahasa Itaiia atau sebaliknya. Atau penerjemahan ini dapat dilakukan apabila bik Bahasa sumber maupun Bahasa sasaran mempunyai latar belakang budaya yang sama seperti Indonesia dan Malaysia. Namun apabila antar Bahasa sumber (ST) dan Bahasa sasaran (TT) tidak termasuk dalam satu rumpun Bahasa yang sama dan tidak mempunyai latar belakang budaya yang sama maka penerjemahan ini tidak layak dilakukan. Misalnya:

ST: Meja itu berwarna hijau

TT: The table is green

Dilihat dari TT Bahasa Inggris maka hasil terjemahan literal masih dapat diterima namun apabila

ST: Mereka membawa kasus itu ke meja hijau

TT: They took the case to green table.

Hasil dari terjemahan literal diatas tentunya sangatlah tidak tepat. Seharusnya penerjemahan tersebut adalah TT: They took the case to the court.

\section{d. Transposition}

Transposition adalah proses penerjemahan dimana suatu jenis kata digantikan dengan jenis kata yang lain dengan tanpa merubah pesan dari ST. Prosedure ini diperkenalkan oleh Venay and Dalbernet. Pergantian disini senada dengan theory Catford (1965) tentang Translation shift dimana dalam teorinya beliau membagi translation shift menjadi dua pembagian yaitu 1) Level shift dan 2) Category shift. Level shift terjadi Ketika Grammar diterjemahkan menjadi lexis atau kata. Misalnya:

ST: She has lived in Jakarta for 10 years.

TT: Dia sudah tinggal di Jakarta selama 10 tahun.

Perhatikan kata yang digarisbawahi tersebut. Dari ST atau Bahasa sumber pembentukan has lived atau Preset Perfect yang merupakan bagian dari Grammar diterjemahkan menjadi kata sudah tinggal dalam TT Bahasa Indonesia. Contoh kasus yang sama juga bisa kita lihat pada penerjemahan Present Progressive dan Passive voice.

Sedangkan Category shift dibagi menjadi 1) Class shift, 2) Structure shift, 3) Unit shift dan 4) intra System shift. Dalam Class shift perubahan antara ST dan TT terjadi Ketika jenis katadari ST berubah ke jenis kata yang lain dalam TT. Misalnya

ST: Coordinating minister

$\mathrm{TT}$ : Meteri yang mengkoordinasi (Literal Translation) maka sangat tidak equivalensi atau setara karena dalam Sistem cabinet kita tidak ditemukan istilah tersebut. Maka penerjemahan yang equivalensi adalah

TT: Mentri coordinator

Dalam ST kata coordinating adalah kata kerja, berubah menjadi coordinator 
Dalam TT Inggris yang berjenis kata benda. Contoh-contoh yang lain banyak sekali seperti medical student diterjemahkan menjadi mahasiswa kedokteran, technical meeting diterjemahkan rapat tehnis, electrical engineer, insinyur kelistrikan dan lain-lain.

Structure shift adalah pegeseran penerjemahan yang paling banyak terjadi terutama yang berhubungan dengan grammar dan structure. Misalnya dalam Bahasa Inggris susunan suatu kalimat terdiri dari $\mathrm{S}+\mathrm{V}+\mathrm{O}$ tetapi apabila diterjemahkan dalam Bahasa Perancis menjadi $\mathrm{O}+\mathrm{V}+\mathrm{S}$. Atau dalam struktur kalimat tanya dalam Bahasa Inggris dengan kata tanya kecuali yang menggunakan who adalah sebagai berikut: Kata tanya + tobe/to do + Sujek+ Kata Kerja + Ket Contoh: Where do you live? Dalam Bahasa Indonesia tidak ada yang Namanya kata kerja bantu baik yang berbentuk to do atau to be. Maka struktur kalimat tanya dalam Bahasa Indonesia adalah Kata tanya + Subjek + Kata kerja + Complement. Jadi untuk TT diatas akan diterjemahkan Where do you live?

Demikian juga pada pembentukan phrase. Dalam Bahasa Inggris menggunakan susunan modifier + Noun atau menerangkan + diterangkan. Misalnya: beautiful girl. Sedangkan dalam Bahasa Indonesia menggunakan sebaliknya yaitu Noun + modifier. Jadi untuk phrase diatas diterjemahkan gadis cantik.
Translation shift selanjutnya adalah unit shift. Shift ini terjadi apabila adanya suatu pergeseran unit penerjemahan baik pergeseran keatas maupun kebawah. Berikut ini adalah urutan unit penerjemahan dari yang paling kecil.

1. Prefix, suffix, infix dan con-fix

2. Word

3. Phrase

4. Clause

5. Sentence

6. Paragraph

Untuk mendapatkan Formal quivalence menurut Vinay dan Dalbernet (1960) atau Catford (1965) perubahan unit penerjemahan tersebut disebut dengan unit shift. Misalnya satu kata diterjemahkan menjadi phrase cotohnya gravitation diterjemahkan gaya Tarik bumi atau prefix diterjemahkan menjadi kata contohnya prefix re dalam Bahasa Inggris diterjemahkan menjadi kata lagi dalam Bahasa Indonesia. Contoh yang lain adalah kalimat I don't know diterjemahkan menjadi kata “entahlah" dalam TT Indonesia.

Shift yang terakhir adalah Intra System shift. Pergeseran ini terjadi dalam system internal Bahasa itu sendiri. Misalnya dalam pembentukan kata benda plural dalam Bahasa Indonesia dilakukan cukup dengan mengulang kata benda tadi. Misalnya kata meja berarti meja singular sedangkan bentuk jamak atau pluralnya adalah meja-meja. Buku, buku-buku, 
teman, teman-teman dan lain sebagainya. Kemudaian mari kita perhatikan pembentukan kata jamak dalam Bahasa Indonesia selanjutnya apabila diikuti dengan kata bilangan. Misalnya kalimat Saya mempunyai tiga buah mobil. Kalau ada kata bilanya yang menunjukkan lebih dari satu atau penunjuk jamak maka kata bendanya dalam Bahasa Indonesia akan merubah menjadi bentukk singular. Yaitu tiga buah mobil. Bukan tiga buah mobil-mobil. Tetapi apabila kita bandingkan dengan TT Inggris, dimana pembentukan jamak dalam Bahasa Inggris akan jauh lebih komplek dan perlu perhatian yang khusus untuk dipelajari. Dimana dalam Bahasa Inggris kata benda dibagi menjadi kata benda dapat dihitung dan kata benda yang tidak dapat dihitung. Tentunya untuk pembentukan jamak hanya kata benda yang dapat dihitung saya yang dapat dirubah. Ada regular plural dimana kata benda tersebut bisa ditambahkan dengan $s$ atau es misalnya book, table, chair, bag, box menjadi books, tables, chairs, bags dan boxes. Sedangkan yang lainnya adalah tidak beraturan dimana harus dimengerti atau dihafalkan misalnya child singular, children plural. Man, woman, (singular). Men, women (jamak). Ada yang antara bentuk singular dan pluralnya sama misalnya deer dan sheep. Tapi pada intinya system pembentukan plural dalam Bahasa Inggris sangat berbeda dengan Bahasa Indonesia apabila diikuti oleh kata penunjut jamak (Plural modifier). Misalnya

ST: I have ten bags

TT: saya mempunya sepuluh buku.

Sekilas dalam TT Indonesia memang tidak ada permasalahan, namun kalau kita perhatikan kata bags (dalam bentuk jamak) diterjemahkan menjadi buku dalam dalam bentuk singular. Mestinya kata tersebut diterjemahkan tas-tas karena bentuknya jamak, namun apabila ini terjadi maka hasil terjemahan tersebut tidak equivalensi atau tidak termasuk dalam formal correspondence (Catfort 1960). Hal ini terjadi karena adanya kata bilangan sepuluh. Kata tersebut sebagai penunjuk bentuk jamak. Maka dalam Bahasa Indonesia apabila ada kata penunjuk jamak seperti kata banyak, beberapa, lima dan lain lain, bentuk kata bendanya harus Kembali ke bentuk singular.

\section{e. Modulation}

Modulation adalah variasi bentuk pesan yang yang terjadi apabila hasil terjemahan sudah benar tetapi masih dirasakan kurang cocok atau terkesan dipaksakan dalam Bahasa sasaran. Modulasi dilakukan dengan cara merubah sudut pandang hasil terjemahan misalnya dengan merubah kalimat positive menjadi negative atau sebaliknya (Vinay and Dalbernet: 1960). Contoh:

ST: I cut my little finger

TT: Jari saya terpotong. 
Vol. 3 No. 1

Juni 2021

e- ISSN 2685 - 0559

p- ISSN 2684 - 673X

Kalau diterjemahkan TT

Indonesia "Saya memotong jari kelingking saya" maka kalimat tersebut terkesan sangat dipaksakan karena berarti ada unsur saya sengaja memotongnya. Padahal dalm konteknya tidak ada unsur kesengajaan. Dalam ST Inggris kalimat tersebut mengandung makna saya tidak sengaja melakukannya.

ST: I left my laptop at canteen

$\mathrm{TT}$ : Laptop saya tertinggal di kantin.

Sama dengan kalimat sebelumnya, hasil terjemahan TT Indonesia juga menyatakan adanya unsur ketidak sengajaan meninggalkan laptop tersebut di kantin.

\section{f. Equivalence}

Contoh klasik dariequivalensi adalah apabila kita mendengar suatu bunyi letusan dalam Bahasa Indonesia apabila ditrakskripkan menjadi "door" tetapi dalam Bahasa inggris "bang". Atau misalnya secara tidak sengaja jari tangan kita terkena palu Ketika kita memasang bingkai photo di dinding. Maka akan terdengar suara "aduh" sedangkan pada kondisi yang sama dalam Bahasa Inggrisnya adalah "Ouch".

Contoh Equivalensi juga terdapat

pada suara binatang

\begin{tabular}{|c|c|}
\hline Indonesia & Equivalent \\
\hline & English \\
\hline $\begin{array}{l}\text { Gug-gug (suara } \\
\text { anjing) }\end{array}$ & wuff \\
\hline $\begin{array}{l}\text { Kokuruyuk } \\
\text { (ayam jantan) }\end{array}$ & Cock-a-dodle-do \\
\hline
\end{tabular}

Meong (kucing) Miaow

Contoh lain dari equivalensi juga dapat dilihat dari kata-kata bijak seperti:

\begin{tabular}{|c|c|}
\hline Indonesia & $\begin{array}{l}\text { English } \\
\text { Equivalence }\end{array}$ \\
\hline $\begin{array}{l}\text { Buah jatuhnya } \\
\text { tidak jauh dari } \\
\text { pohonnya }\end{array}$ & $\begin{array}{l}\text { Like father like } \\
\text { son }\end{array}$ \\
\hline $\begin{array}{l}\text { Dimana bumi } \\
\text { dipijak, disitu } \\
\text { langit dijunjung }\end{array}$ & $\begin{array}{l}\text { When in Rome } \\
\text { act like a Roman }\end{array}$ \\
\hline $\begin{array}{l}\text { Menyelam } \\
\text { sambal minum } \\
\text { air }\end{array}$ & $\begin{array}{l}\text { To kill some } \\
\text { birds with one } \\
\text { stone }\end{array}$ \\
\hline
\end{tabular}

Penggunaan equivalensi dalam majas simile

English Indonesian Equivalence

As easy as Semudah $A B C$ membalikkan telapak tangan

As black as Sehitam arang

coal

As light as Seringan kapas

feather

As tall as Setinggi menara

giraffe

As white as Seputih salju

ghost

As hot as hell Sepanas bara api

As sweet as Semanis madu

sugar

g. Adaptation

\begin{tabular}{lrr}
\multicolumn{2}{c}{ Kadang-kadang } & seorang \\
penerjemah & harus & dapat \\
menciptakan & suatu & situasi \\
sedemikian & rupa agar & hasi
\end{tabular} terjemahannya dapat diterima dalam kontek budaya, adat dan kebiasaan Bahasa sasaran dan 
supaya terjemahnnya equivalen. Contohnya seorang ayah yang berkewarganegaraan Inggris yang sudah lama tidak bertemu dengan anak gadisnya mencium anak tersebut pada bibirnya. Hal ini bisa dilakukan dengan menerjemahkannya menjadi "Ayahnya menciumnya di keningnya".

Adaptation supaya

equivalnesi dalam terjemahan harus dilkukan juga terutama pada alat ukur yang berlaku di suatu daerah misalnya untuk satuan pengukurang Panjang di Indonesia menggunakan meter dan lain-lain.

\section{Contoh}

ST: The snake they cough was 12 feet.

TT: Ular yang mereka tangkap pangjangnya 3,7 meter.

Sedangkan dalam contoh kalimat ke tiga apabila 12 feet diterjemahkan menjadi 12 kaki maka akan membingungkan pembaca Bahasa sasaran karena dalam Bahasa Indonesia untuk satuan Panjang yang tepat disini adalah menggunakan meter. Hal ini juga terjadi pada satuan berat yang umum berlaku di Indonesia, satuan tersebut adalah gram, ons, kilogram, kwintal dan ton. berlaku di Indonesia. Misalnya bentuk satuan yang berlaku di negara Inggris adalah Lbs atau pound. Maka apabila dalam ST ada menggunakan satuan berat tersebut harus dikonversi dengan satuan yang berlaku di Inonesia yang sudah disebutkan diatas. Contoh

ST: His weight is 150 pounds.

TT: Beratnya 75 kilogram. Dan sebagainya.

\section{REFFERENCES}

Campbell, L. (1998). Historical Linguistics. Edinburgh. Edinburgh University Press

Catford, John C. 1965. A linguistic theory of translation: An essay in applied linguistics. London: Oxford University.

Hatim, B and Munday, J. (2004). Translation An Advanced Resource Book. New york. Roulegde.

Kridalaksana, H. (1993). Kamus Linguistik Edisi ke 3. Jakarta. PT Gramedia Pustaka Utama.

Munday, J. (2016). Introducing Translation Studies: Theories and Applications. New york. Roulegde.

Vinay, J.-P. and J. dalam Venuti, L. (2000). The Translation Studies Readers. London. Reouledge.

Vinay, J.-P. and J.(1995) Comparative Stylistics of French and English: A Methodology for Translation, trans. and eds J.C.Sager and M.J.Hamel, Amsterdam: Benjamins. 